\title{
A New State Record of the Cuban Treefrog, Osteopilus septentrionalis (Duméril and Bibron 1841) (Hylidae), in North Carolina
}

Michael C. Granatosky ${ }^{1}$ and Kenneth L. Krysko ${ }^{2}$

${ }^{1}$ Department of Evolutionary Anthropology, Duke University, Durham, North Carolina 27708, USA (michael.granatosky@duke.edu)
${ }^{2}$ Division of Herpetology, Florida Museum of Natural History, University of Florida, Gainesville, Florida 32611, USA (kenneyk@ufl.edu)

$\mathrm{T}$ The Cuban Treefrog, Osteopilus septentrionalis (Duméril and Bibron 1841) (Fig. 1), is native to Cuba, the Bahamas, and the Cayman Islands, and is well known for its invasive capabilities (Meshaka et al. 2001). Barbour (1931) was the first to report the presence of this species in the United
States (Monroe County, Florida), and this invasive amphibian subsequently has spread rapidly throughout the extreme southeastern United States (Welker 2004). The successful expansion of the species' introduced range likely can be attributed to high fecundity, an ability to out-compete native anurans

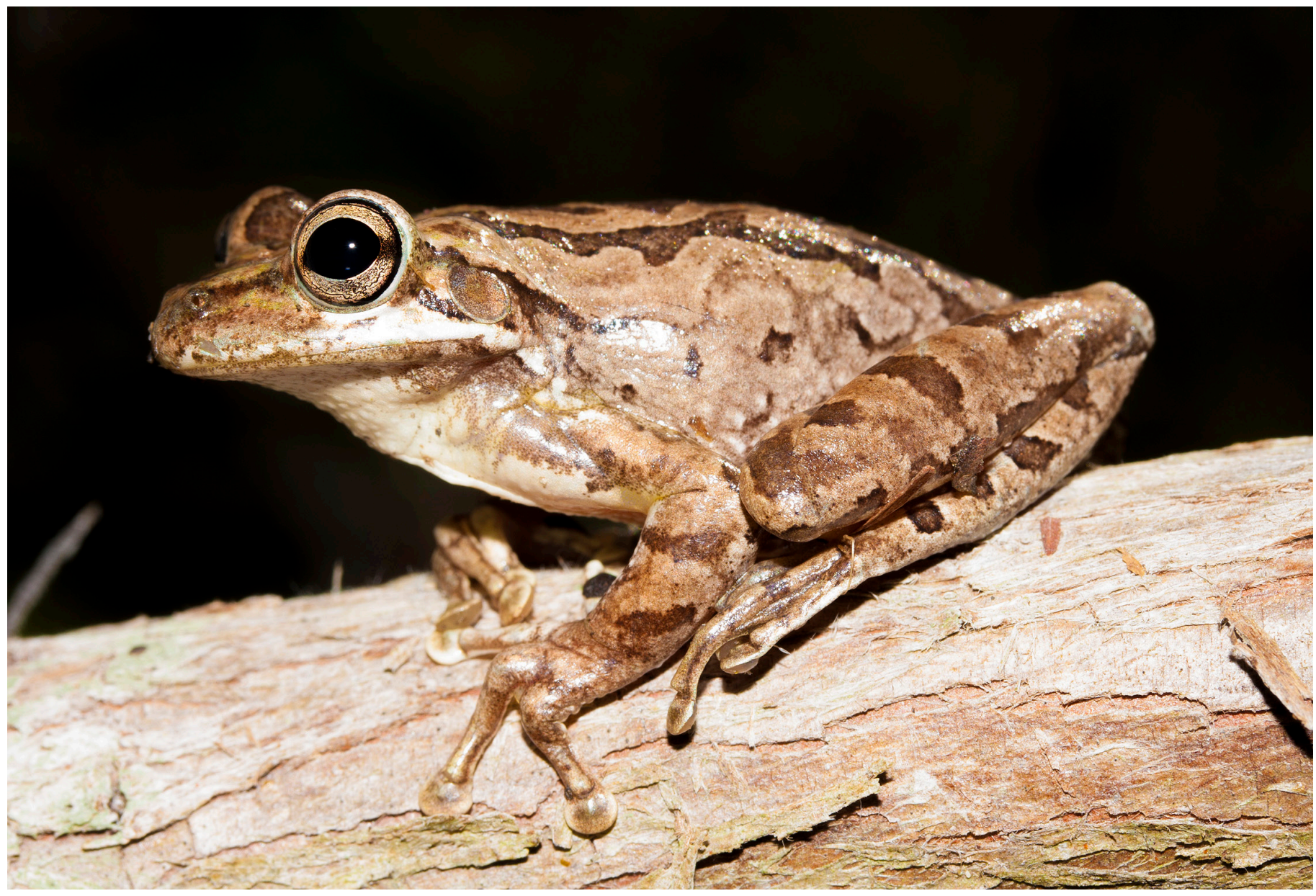

Fig. 1. A Cuban Treefrog (Osteopilus septentrionalis) from Gainesville, Alachua Co., Florida. Motor vehicle transport of cargo and ornamental plants has been instrumental in the spread of this species in Florida and is the likely introduction pathway for these frogs into North Carolina. Photograph by Kenneth L. Krysko. 
and tolerate cold weather, and the capacity to prey upon an array of native species (Austin 1973; Ashton and Ashton 1988; Meshaka 1994, 1996; Campbell 1999; Vargas Salinas 2006; Granatosky and Krysko 2011; Granatosky et al. 2011). The spread of the species appears to rely largely on anthropogenic transport via motor vehicles or potted landscaping vegetation (Lever 2003, Kraus 2009, Krysko et al. 2011, Meshaka 2011).

Although sightings and captures of $O$. septentrionalis in North Carolina have occurred (J.C. Beane, pers. comm.), no voucher specimens or published verifications currently exist. Therefore, we report the first voucher specimen of $O$. septentrionalis from a single location in Chapel Hill, North Carolina. This represents the first recorded sighting of $O$. septentrionalis in the state and likely represents a recent and isolated introduction.

On 04 January 2014, MCG collected an Osteopilus septentrionalis (UF-Herpetology 172200) from Townhouse Apartments of Chapel Hill, 425 Hillsborough Street, Chapel Hill, Orange County, North Carolina (35.919372, -79.052568; Datum WGS84). The frog was in a lethargic state crawling on a sidewalk. No additional individuals were observed. The juvenile (< $44 \mathrm{~mm}$ SVL; Meshaka 2001) was deposited in the Division of Herpetology at the Florida Museum of Natural History. Paul E. Moler (pers. comm.) confirmed our identification.

Because only a single juvenile individual was found at the collection site, we believe that this observation represents a single introduction event. The fact that the specimen was collected in an apartment complex in close proximity to the University of North Carolina at Chapel Hill during early January when students were returning from winter break suggests that the likely introduction pathway was via motor vehicle transport from an area with established populations of Cuban Treefrogs. The introduction of nonnative amphibians and reptiles by means of cargo or ornamental plant transfer, at least in Florida, is recognized as a major introduction pathway second only to the pet trade (Krysko et al. 2011). Also, North Carolina clearly is an area at potential risk of continuing ecological invasions by exotic herpetofauna (Beane and Corey 2010, Beane 2013, Granatosky and Krysko 2013). The scientific community should promote early detection and foster public knowledge about the ecological dangers of invasive species.

\section{Acknowledgments}

We thank Jeffery Beane for information on our new state record and Paul E. Moler for confirming the identification of the specimen.

\section{Literature Cited}

Ashton, R.E., Jr. and P.S. Ashton. 1988. Handbook of Reptiles and Amphibians of Florida. Part Three: The Amphibians. Windward Publ. Co., Miami, Florida.

Austin, D.F. 1973. Range expansion of the Cuban Treefrog in Florida. Florida Naturalist 46:28.

Beane, J.C. and J.E. Corey III. 2010. New geographic distribution records for reptiles from North Carolina, USA. Herpetological Review 44:388-391.

Beane, J.C. 2013. New geographic distribution records for reptiles from North Carolina, USA. Herpetological Review 44:478-481.

Barbour, T. 1931. Another introduced frog in North America. Copeia 1931:140.

Campbell, R. 1999. Geographic distribution. Osteopilus septentrionalis (Cuban Treefrog). Herpetological Review 30:50-51.

Granatosky, M.C. and K.L. Krysko. 2011. Ontogenetic behavioral shifts in habitat utilization of treefrogs (Hylidae) in North-central Florida. Reptiles \& Amphibians 18:20-27.

Granatosky, M.C. and K.L. Krysko. 2013. The Brown Anole, Anolis sagrei Duméril and Bibron 1837 (Dactyloidae), state record and introduction pathway. Reptiles \& Amphibians 20:190-191.

Granatosky, M.C., L.M. Wagner, and K.L. Krysko. 2011. Osteopilus septentrionalis (Cuban Treefrog). Diet. Herpetological Review 42: 90.

Kraus, F. 2009. Alien Reptiles and Amphibians, a Scientific Compendium, and Analysis. Invading Nature: Springer Series in Invasion Biology 4. Springer, Dordrecht, The Netherlands.

Krysko, K.L., J.P. Burgess, M.R. Rochford, C.R. Gillette, D. Cueva, K.M. Enge, L.A. Somma, J.L. Stabile, D.C. Smith, J.A. Wasilewski, G.N. Kieckhefer III, M.C. Granatosky, and S.V. Nielsen. 2011. Verified non-indigenous amphibians and reptiles in Florida from 1863 through 2010: Outlining the invasion process and identifying invasion pathways and stages. Zootaxa 3028:1-64.

Lever, C. 2003. Naturalized Reptiles and Amphibians of the World. Oxford University Press, Oxford, UK.

Meshaka, W.E., Jr. 1994. Ecological correlates of successful colonization in the life history of the Cuban Treefrog, Osteopilus septentrionalis (Anura: Hylidae). Dissertation, Florida International University, Miami.

Meshaka, W.E., Jr. 1996. Vagility and the Florida distribution of the Cuban Treefrog (Osteopilus septentrionalis). Herpetological Review 27:37-40.

Meshaka, W.E., Jr. 2001. The Cuban Tree Frog in Florida. Life History of a Successful Colonizing Species. University Press of Florida, Gainesville.

Meshaka, W.E., Jr. 2011. A runaway train in the making: Exotic amphibians, reptiles, turtles, and crocodilians of Florida. Monograph 1. Herpetological Conservation and Biology 6:1-101.

Meshaka, W.E., Jr., B.P. Butterfield, and J.B. Hauge. 2001. The Exotic Amphibians and Reptiles of Florida. Krieger Publishing, Inc., Melbourne, Florida.

Vargas Salinas, F. 2006. Breeding behavior and colonization success of the Cuban Treefrog Osteopilus septentrionalis. Herpetologica 62:398-408.

Welker, M.E. 2004. Geographic distribution. Osteopilus septentrionalis (Cuban Treefrog). Herpetological Review 35:283. 